\title{
Labor Induction with Oral Misoprostol in Term Pregnancy: A Clinical Trial
}

\author{
Teddy Habiragi Matega',2, Mike-Antoine Alongo Maindo', Jean-Didier Nguma Bosenge1, \\ Albert Okolongo Wembakoy ${ }^{3}$, Noël Otuli Labama', Jean-Jeannot Syhalikyolo Juakali' \\ Antoine 0’Yandjo Modia', Jean-Pascal Okenge Manga', Gédéon Bosunga Katenga ${ }^{1}$
}

\footnotetext{
${ }^{1}$ Department of Gynecology and Obstrics, Faculty of Medecine and Pharmacy, University of Kisangani, Kisangani, Democratic Republic of Congo

${ }^{2}$ Congolaise National Police, Provincial Hospital of Tshopo, Kisangani, Democratic Republic of Congo

${ }^{3}$ Higher Institute of Medical Techniques of Haut Uélé, Isiro, Democratic Republic of Congo

Email: teddymatega@gmail.com
}

How to cite this paper: Matega, T.H. Maindo, M.-A.A., Bosenge, J.-D.N., Wembakoy, A.O., Labama, N.O., Juakali, J.-J.S., Modia, A.O., Manga, J.-P.O. and Katenga, G.B. (2021) Labor Induction with Oral Misoprostol in Term Pregnancy: A Clinical Trial. Journal of Biosciences and Medicines, 9, 74-88.

https://doi.org/10.4236/jbm.2021.910007

Received: August 24, 2021

Accepted: October 17, 2021

Published: October 20, 2021

Copyright (c) 2021 by author(s) and Scientific Research Publishing Inc. This work is licensed under the Creative Commons Attribution International License (CC BY 4.0).

http://creativecommons.org/licenses/by/4.0/

\section{(c) (i) Open Access}

\begin{abstract}
Introduction: Induction of labor has become an increasingly utilized obstetric intervention in developed countries. It contributes to reduce the maternal and perinatal morbidity and mortality. Dinoprostone derivatives are often used under cardiotocography. In poor countries, health structures have neither fetal monitoring, nor means of preserving Dinoprostone derivatives. Misoprostol therefore constitutes an alternative. This study seeks to establish the efficacy and safety of oral Misoprostol and to assess maternal and perinatal prognosis in an area with limited resource. Methods: This is a multi-center clinical trial, conducted in 3 hospitals centers in Kisangani, Tshopo Province/Democratic Republic of Congo from December 1, 2020 to May 31, 2021. Our sample was constituted with 68 pregnant women with term pregnancy. Fifty micrograms of Misoprostol was administered orally. The data were collected prospectively, their encoding was carried out on an Excel sheet 2013 and their analysis carried out using the EPI INFO software. Results: The average age of the pregnant women was $23.17 \pm 5.76$ years. The average parity was $1.02 \pm 1.2$. The average body mass index (BMI) was $24.98 \pm 2.55 \mathrm{Kg} / \mathrm{m}^{2}$. $66(97.1 \%)$ patients had received a maximum of 3 doses of Misoprostol. Out of the 16 parturients who received 3 doses or more, $11(68.8 \%)$ had a BMI $\geq$ 25. The average duration of labor was $16.03 \pm 7.99$ hours. 66 (97.1\%) pregnant women had delivered vaginally. 57 (83.8\%) patients delivered within 24 hours. Out of the 11 patients who delivered after 24 hours, 7 (63.6\%) had a $\mathrm{BMI} \geq 25$. The induction failure rate was $2.9 \%$ (2 patients). 2 (2.9\%) fetuses had presented pathological modification of fetal heart rate (FHR). 2 (2.9\%) patients had undergone cesarean section. Conclusion: Labor induction with
\end{abstract}


oral Misoprostol is effective and associated with low maternal and perinatal morbidity. A BMI $\geq 25 \mathrm{~kg} / \mathrm{m}^{2}$ increases the number of doses to be given and the duration of labor.

\section{Keywords}

Misoprostol, Efficacy, Labor, BMI, Kisangani

\section{Introduction}

Labor is the set of mechanical and physiological phenomena characterized by the apparition of forceful and painful uterine contractions that affect cervical dilatation and cause the fetus to descend through the birth canal [1] [2]. These phenomena normally occur spontaneously in a term pregnancy. However, when the pregnancy exceeds 40 weeks, maternal risks such as instrumental extractions, cesarean section, chorioamnionitis, postpartum endometritis, and perinatal risks such as fetal distress, macrosomia, fetal death, management of the newborn in neonatal intensive care increase [3].

Pregnancy may be prolonged ( $\geq 41$ weeks) or going to postterm ( $\geq 42$ weeks) thus indicating labor induction [4] [5]. Likewise, for personal convenience, or if the pregnant woman has risk factors such as prelabor rupture of membranes (PROM), gestational diabetes, gravidic hypertension, preeclampsia, or in twin pregnancy, when fetal macrosomia is suspected, or intrauterine growth retardation (IUGR), labor may be induced [2] [6].

Labor induction is a medical intervention that consists of using a drug or non-drug method to induce uterine contractions in order to help the pregnant woman to have a vaginal delivery [7]. This intervention is aimed at pregnant women who have not started labor, regardless of the state of the membranes [7]. The labor induction is successful when a vaginal delivery is obtained within 24 hours [8].

According to the World Health Organization (WHO) [9], the prevalence of labor induction in developed countries is of an average of $25 \%, 11.4 \%$ in Latin America, $12.1 \%$ in Asia. In developing countries, the prevalence would be lower and others would have a similar prevalence as in developed countries. In Sri Lanka, the prevalence of induction of labor is $35.5 \%$ [10] and in the United States of America, it's 25\% [11]. In Africa, the prevalence would vary between $1.4 \%-6.8 \%$ with an average of $4.9 \%$ [12]. In Nigeria, a study conducted in a tertiary hospital in Lagos found a prevalence of $16.7 \%$ [13]. However, in the Democratic Republic of Congo (DRC), a prevalence of $3.2 \%$ was found at the University Clinics of Kinshasa [14]. In Kisangani, in the Eastern region of the DRC, we did not access to data related to labor induction.

To onset the labor induction, WHO recommends using oxytocin solution, prostaglandins or artificial rupture of membranes [15]. Synthetic prostaglandins have been widely used over the last 20 years in labor induction due to their 
greater efficacy [16] [17].

Synthetic prostaglandins used in obstetrics are the analogues of prostaglandin E1 (Dinoprostone) and the analogues of prostaglandin E1 (Misoprostol) [18]. Dinoprostone is expensive, requires storage at temperatures ranging from $2^{\circ} \mathrm{C}$ $8^{\circ} \mathrm{C}[19]$ hence the difficulty of using it in low income environments. Misoprostol therefore constitutes an alternative. Among the advantages of Misoprostol are its stability at ambient temperature, the rapidity of its action, its multiple potential routes of administration (oral, buccal, sublingual, vaginal, rectal) and its low cost [8] [20].

From the beginning of the labor induction process, woman should be admitted to hospital, she should be carefully assessed for evidence of fetal compromise. This should include electronic FHR monitoring for 30 minutes if available. Once a Misoprostol regimen has been started, the woman must be monitored the FHR and uterine activity closely [21].

WHO [15] recommends the use of Misoprostol at low doses and monitoring of labor by the cardiotocogram to early detect pathological modification of fetal heart rate (FHR) and uterine hyperstimulation which can lead to rupture of the uterus. For this, WHO [15] and the International Federation of Gynecologists and Obstetricians (FIGO) [22] recommend doses of 25 microgram ( $\mu \mathrm{g}$ ) vaginally every 6 hours or $25 \mu$ g orally every 2 hours.

However, there is no evidence about the optimal number of doses to be administered to increase the rate of vaginal delivery [23]. It is the same for the frequency and the route of administration [24] [25]. A Cochrane analysis conducted in 2006, including four tests (474 women) recommended that the dose of oral Misoprostol would not exceed $50 \mu \mathrm{g}$ [26].

Misoprostol with low dose is well tolerated, but its use is limited if the pregnant woman has a scarred uterus. Misoprostol may be associated with hypercinesia, uterine hypertonia, pathological modifications of FHR and this depends on the dose and route of administration, which may be accompanied by an emergency cesarean section whereas the latter may not be indicated [27].

Oral Misoprostol is rapidly absorbed and reaches the plasmatic pic 30 minutes after its administration. It then binds to plasma proteins in a proportion less than $90 \%$, which is the inactive form, thereby reducing the plasma concentrations of the active metabolite as well as its action on smooth muscle fibers [19]. As a result, its contracting action on the uterus would be reduced, thus reducing the risk of hyperstimulation and pathological modification of FHR compared to other routes if it was administered with the same doses and at the same frequency.

However, the Misoprostol available in our environment is of $200 \mu \mathrm{g}$, hence the difficulty of dividing into 8 in order to obtain the dose of $25 \mu \mathrm{g}$ as recommended by the WHO [15] and FIGO [22], and several health structures in under-equipped settings do not have a cardiotocogram for monitoring of the FHR and uterine contractions, which can increase the risk of maternal and perinatal complica- 
tions.

That is why we wanted to know if $50 \mu \mathrm{g}$ of oral Misoprostol could be effective for labor induction, and to assess the associated maternal and perinatal prognosis in under-equipped settings.

\section{Material and Methods}

These are the preliminary results of a clinical trial, conducted at the Kabondo General Reference Hospital (GRH), at the Alwaleade and Saint-Joseph Reference Health Centers in Kisangani, Tshopo Province, Democratic Republic of Congo, from December 1, 2020 to May 31, 2021. Data collection was prospective. The population of the study was pregnant women with term pregnancies admitted to one of the maternities of the selected health structures and who had undergone antenatal consultations. The sample consisted of 68 pregnant women with term pregnancies (38 - 41 weeks).

Were included, nulliparous, pauciparous and multiparous who had a single fetus, with normal fetal heart rate (110 - 160 per minute), cephalic presentation, without medical indication for labor induction and who had signed the informed consent.

Excluded were large multiparous, pregnant women with multiple pregnancy, hypertension, diabetes, large or small pregnant uterus, presentation other than cephalic, FHR disturbances before induction, placenta praevia, pregnancy in a fibromyomatous uterus, foeto-pelvic disproportion, abnormalities pelvis and cases of fetal death.

In the operational setting, the socioeconomic parameters were evaluated according to the score of Traissac et al. [28], the large multiparous were pregnant women who had already delivered more than five times. We had induced labor with Miso ${ }^{\circledast} 200$ manufactured by Mylan Laboratories Ltd. Gujarat. India. Batch No 9415A009A (INN: Misoprostol), we divided the tablet by 4, thus obtaining 50 $\mu \mathrm{g}$ which was administered orally with a cup of water and the pregnant woman took again 1/4 tablet every 6 hours until obtaining effective uterine contractions, without exceeding 3 doses. Uterine contractions were said to be effective when one had at least 3 uterine contractions every 10 minutes with an average duration of 45 seconds.

For the efficacy of oral Misoprostol, we assessed the number of dose administered, the time to onset of the first uterine contractions compared to the first dose, the duration of labor and vaginal delivery rate.

For the safety of oral Misoprostol, we assessed uterine hyperstimulation rate, uterine pre-rupture or rupture, cesarean section, pathological changes due to FHR, meconium staining of amniotic fluid, Apgar score and neonatal management.

Uterine hyperstimulation was the association or not of hypercinesia and hypertonia. It was considered as failure of induction when there was no occurrence of uterine contractions after administration of 3 successive doses. We pro- 
ceeded to an active management of the third period of delivery to prevent delivery hemorrhages. The body mass index (BMI) was evaluated in relation to the results of Ferrazzi et al. [29] which suggest that a BMI $>25 \mathrm{Kg} / \mathrm{m}^{2}$ at term pregnancy increases the risk of failure to induce labor, prolonged labor and high cesarean section rate.

The data were collected using a standard protocol including socio-anthropometric, gyneco-obstetric parameters, labor process, delivery route, maternal and perinatal prognosis. The data collected were encoded on an Excel 2013 sheet and analyzed using EPI INFO Version 7.2.2.6 software.

\section{Results}

As shown in Figure 1, on 87 patients which were eligible for labor induction with oral Misoprostol, 19 were exclused whose 3 for gestational hypertension, 2 twin pregnancy, 4 for non-cephalic presentation, 1 for placenta praevia, 1 for gestational diabetes, 2 for foetal death and 6 refused to induce labor. That is why we stayed with 68 patients in whom we induced labor and data analysis.

The age average of pregnant women was of $23.17 \pm 5.76$ years. 44 (64.7\%) of the pregnant women had between 20 - 34 years. 56 (82.4\%) were married, 36 (52.9\%) had no profession, 34 (50\%) had a low socio-economic and secondary level education (Table 1).

The parity average was $1.02 \pm 1.21$ and 50 (73.5\%) patients were nulliparous. The BMI average was $24.98 \pm 2.55 \mathrm{Kg} / \mathrm{m}^{2}$ and $43(63.2 \%)$ pregnant women had an BMI $<25 \mathrm{Kg} / \mathrm{m}^{2}$. The membranes were intact in $62(91.2 \%)$ of pregnant women. Birth weight was $3201.76 \pm 375.778 \mathrm{gr}$ and 58 (85.3\%) newborns had a weight between 2500 and $3500 \mathrm{gr}$ (Table 2).

\section{Relation between BMI, the Number of Doses and the Duration of Labor}

\subsection{Relation between BMI and Number of Doses}

Of 14 patients who received only one dose of Misoprostol, 10 (71.4\%) had a BMI $<25$ and $4(28.6 \%)$ a $\mathrm{BMI} \geq 25.38$ patients received 2 doses among whom 28 (73.7\%) had a BMI $<25$ and $10(26.3 \%)$ had a BMI $\geq 25$. Out of 16 pregnant

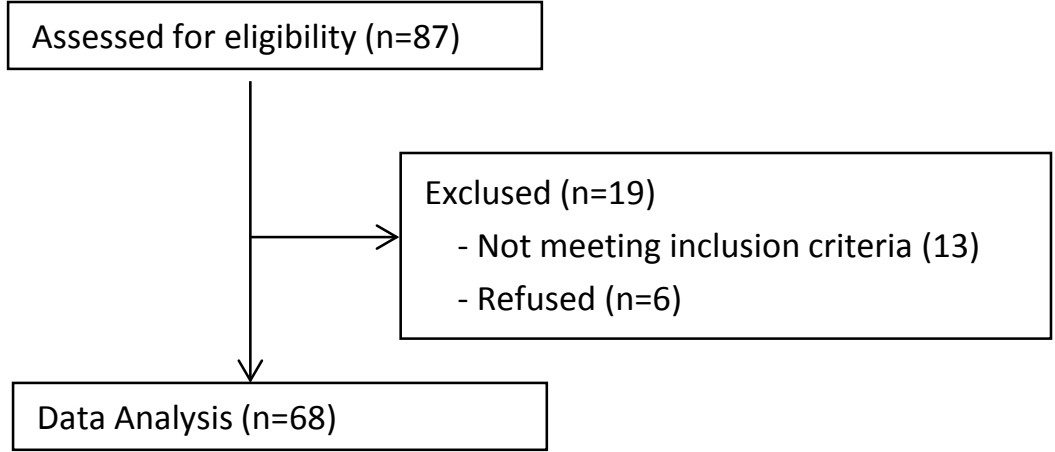

Figure 1. Flow diagram for analysis. 
Table 1. Socio-demographic factors.

\begin{tabular}{|c|c|c|c|c|}
\hline Parameters & $\begin{array}{c}f \\
N=68\end{array}$ & $\%$ & $95 \% \mathrm{CI}$ & Average \pm DS \\
\hline Age (years) & & & & $23.17 \pm 5.76$ \\
\hline$<20$ & 20 & 29.4 & $18.98-41.71$ & \\
\hline $20-34$ & 44 & 64.7 & $52.17-52.17$ & \\
\hline$\geq 35$ & 4 & 5.9 & $1.63-1.63$ & \\
\hline \multicolumn{5}{|l|}{ Marital Status } \\
\hline Married & 56 & 82.4 & $71.20-90.53$ & \\
\hline Single & 12 & 17.6 & $9.47-28.80$ & \\
\hline \multicolumn{5}{|l|}{ Profession } \\
\hline Pupil/Student & 22 & 32.4 & $21.51-44.79$ & \\
\hline without & 36 & 52.9 & $40.45-65.17$ & \\
\hline Salaried & 2 & 2.9 & $0.36-10.22$ & \\
\hline Informal sector & 8 & 11.7 & $5.22-21.87$ & \\
\hline \multicolumn{5}{|l|}{ Socio-economic level } \\
\hline Low & 34 & 50.0 & $61.43-83.50$ & \\
\hline Medium & 32 & 47.1 & $7.28-25.39$ & \\
\hline High & 2 & 2.9 & $5.22-21.87$ & \\
\hline \multicolumn{5}{|l|}{ Education level } \\
\hline Illiterate & 4 & 5.9 & $1.63-14.38$ & \\
\hline Primary & 22 & 32.3 & $21.51-44.79$ & \\
\hline Secondary & 34 & 50.0 & $37.62-62.38$ & \\
\hline Superior & 8 & 11.8 & $5.22-21.87$ & \\
\hline
\end{tabular}

Table 2. Gyneco-obstetrical parameters.

\begin{tabular}{|c|c|c|c|c|}
\hline Parameters & $\begin{array}{c}f \\
N=68\end{array}$ & $\%$ & $95 \% \mathrm{CI}$ & Average \pm SD \\
\hline Parity & & & & $1.02 \pm 1.21$ \\
\hline Nulliparous & 50 & 73.5 & $61.43-83.50$ & \\
\hline Pauciparous & 10 & 14.7 & $7.28-25.39$ & \\
\hline Multiparous & 8 & 11.8 & $5.22-21.87$ & \\
\hline$B M I\left(K g / m^{2}\right)$ & & & & $24.98 \pm 2.55$ \\
\hline$<25$ & 43 & 63.2 & $50.67-74.61$ & \\
\hline$\geq 25$ & 25 & 36.8 & $25.39-49.33$ & \\
\hline \multicolumn{5}{|l|}{ Membranes } \\
\hline Intacts & 62 & 91.2 & $81.78-96.69$ & \\
\hline Ruptured & 6 & 8.8 & $3.31-18.22$ & \\
\hline$P N($ grams $)$ & & & & $3201.76 \pm 375.778$ \\
\hline $2500-3500$ & 58 & 85.3 & $74.61-92.72$ & \\
\hline$>3500$ & 10 & 14.7 & $7.28-25.39$ & \\
\hline
\end{tabular}


women who received 3 doses or more, 5 (31.2\%) had a BMI $<25$ and $11(68.8 \%)$ had a $\mathrm{BMI} \geq 25$.

\subsection{Relation between BMI and the Duration of Labor}

The pregnant women who delivered within the 24 hours were 57 (83.8\%) among which 39 (68.4\%) had a BMI < 25 and 18 (31.6) had a BMI IMC $\geq 25.11$ patients delivered 24 hours after induction among whom 4 (36.4\%) had a BMI $<25$ and 7 (63.6\%) had a $\mathrm{BMI} \geq 25$.

As shown in Table 3, the average of the doses received was $2.09 \pm 0.82$ or $104.5 \pm 41 \mu \mathrm{g}$ of Misoprostol. 66 (97.1\%) patients received 3 doses or less. The evolution of the labor was normal in 66 (97.1\%). Pregnant women who presented an uterine hyperstimulation were $2(2.9 \%)$. The average time to onset uterine contractions was $6.82 \pm 4.00$ and 38 (55.9\%) patients already had uterine contractions after the first dose. 57 (83.8\%) patients delivered within 24 hours. The average labor duration was $16.03 \pm 7.99$ hours. The failure rate of labor induction was $2.9 \%$ ( 2 patients). 66 (97.1\%) patients delivered through vagnal route and only $2(2.9 \%)$ cases of ceasarean sections were recorded. One case indicated for onset failure and the other one for pathological modification of FHR.

During labor, BCF was normal in 66 (97.1\%) patients. 64 (94.1\%) newborns had an Apgar $\geq 7$ the first minute against 2 (2.9\%) for whom the Apgar was weak. At the fifth minute, all the newborns had an Apgar $\geq 7.66$ (97.1\%) newborns had a normal evolution (Table 4).

Table 3. Number of doses received, evolution of labor and maternal prognosis.

\begin{tabular}{|c|c|c|c|c|}
\hline Parameters & $\begin{array}{c}\mathrm{f} \\
\mathrm{N}=68\end{array}$ & $\%$ & $95 \% \mathrm{CI}$ & Average $\pm S D$ \\
\hline Doses of Miso received & & & & $2.09 \pm 0.82$ \\
\hline$\leq 3$ & 66 & 97.1 & $89.78-99.64$ & \\
\hline$>3$ & 2 & 2.9 & $0.36-10.22$ & \\
\hline \multicolumn{5}{|l|}{ Evolution of labor } \\
\hline Normal & 66 & 97.1 & $89.78-99.64$ & \\
\hline Hyperstimulation & 2 & 2.9 & $0.36-10.22$ & \\
\hline Duration $1^{\text {st }} C U$ (hours) & & & & $6.82 \pm 4.00$ \\
\hline $0-6$ & 38 & 55.9 & $43.32-67.92$ & \\
\hline $7-12$ & 22 & 32.4 & $21.51-44.79$ & \\
\hline$\geq 12$ & 8 & 11.7 & $5.22-21.87$ & \\
\hline Duration dose 1 to delivery (hours) & & & & $16.03 \pm 7.99$ \\
\hline$\leq 24$ & 57 & 83.8 & $72.90-91.64$ & \\
\hline$>24$ & 11 & 16.2 & $8.36-27.10$ & \\
\hline Failure Induction & 2 & 2.9 & $0.36-10.22$ & \\
\hline \multicolumn{5}{|l|}{ Delivery route } \\
\hline Vaginal delivery & 66 & 97.1 & $89.78-99.64$ & \\
\hline Ceasarean section & 2 & 2.9 & $0.36-10.22$ & \\
\hline
\end{tabular}


Table 4. Perinatal prognostic.

\begin{tabular}{|c|c|c|c|c|}
\hline Parameters & $\begin{array}{c}f \\
N=68\end{array}$ & $\%$ & $95 \% \mathrm{CI}$ & Averages \\
\hline$F H R$ & & & & $140.94 \pm 4.22$ \\
\hline Normal & 66 & 97.1 & $89.78-99.64$ & \\
\hline Abnormal & 2 & 2.9 & $0.36-10.22$ & \\
\hline \multicolumn{5}{|l|}{$A P G A R\left(1^{\text {st }}\right.$ minute $)$} \\
\hline$\geq 7$ & 64 & 94.1 & $85.62-98.37$ & \\
\hline Abnormal & 4 & 5.9 & $1.63-14.38$ & \\
\hline \multicolumn{5}{|l|}{ APGAR (5 minute) } \\
\hline$\geq 7$ & 68 & 100.0 & $94.72-100.00$ & \\
\hline Abnormal & 0 & 0.0 & $0.00-5.28$ & \\
\hline \multicolumn{5}{|l|}{ Neonatal care } \\
\hline Yes & 2 & 2.9 & $0.36-10.22$ & \\
\hline No & 66 & 97.1 & $89.78-99.64$ & \\
\hline
\end{tabular}

\section{Discussion}

\subsection{Influence of BMI on the Number of Doses}

Beckwith L et al. [30] compared the effect of obesity in labor induction with prostaglandin versus mechanical dilatation and found that obesity was associated with a higher rate of failure to achieve active labor in women undergoing prostaglandin ripening with Misoprostol. In this study, the average BMI was $24.98 \pm 2.55 \mathrm{~kg} / \mathrm{m}^{2} .43(63.2 \%)$ of pregnant women had a BMI $<25 \mathrm{~kg} / \mathrm{m}^{2}$ and 25 (36.8\%) had a $\mathrm{BMI} \geq 25 \mathrm{~kg} / \mathrm{m}^{2}$. Of 14 patients who received only one dose of Misoprostol, $71.4 \%$ had a BMI $<25 \mathrm{~kg} / \mathrm{m}^{2}$. At 2 doses, $28(65.1 \%)$ had a BMI $<$ 25 . Hence, a BMI $<25$ is associated with a reduction in the number of doses to be administered. However, of 16 patients who received 3 doses or more, 11 $(68.8 \%)$ had a BMI $\geq 25 \mathrm{~kg} / \mathrm{m}^{2}$. From the above, BMI $\geq 25$ is associated with an increase in the number of doses. Lassiter J.R. et al. [31] found that women with higher BMI required more doses of Misoprostol, longer duration of oxytocin administration prior to delivery.

Ferrazzi et al. [29] found that BMI $\geq 25$ was a risk factor for prolonged labor which can increase the number of doses to be administered if the uterine contractions are not effective.

\subsection{Relation between BMI and Labor Duration}

Of the 57 patients who delivered within 24 hours, 39 (68.4\%) had a BMI $<25$. These results could also be related to the sample size of pregnant women with BMI $<25$ which represented $63.2 \%$ (43 patients). Of 11 patients who delivered after 24 hours, 7 (63.6\%) had a BMI $\geq 25$. Maged AM et al. [32] induced labor in postdate pregnancy in obese woman and found that the duration till of vaginal 
delivery was higher compared to non-obese woman. Ferrazzi et al. [29] found that the BMI $\geq 25$ on a postterm pregnancy was à risk factor of prolonged duration of labor induction. They found that in nulliparous patients, if the BMI $\geq 30$, the induction time was high as well as the number of doses received (AdjOR 2.4, 95\% CI 1.02 - 5.67), it is even in multiparous patients if BMI $\geq 30$ (AdjOR 4.24, $95 \%$ CI 1.02 - 17.6). Pevzener et al. [33] evaluated the efficacy of dinoprostone and Misoprostol via the vagina in assessing the occurrence of vaginal delivery after induction in 1274 patients and found that a BMI $<30 \mathrm{~kg} / \mathrm{m}^{2}$ was associated with a greater chance of giving birth vaginally (odds-ratio [OR]: 1.95; 95\% CI: $1.32-2.22 ; \mathrm{p}<0.01)$. Despite being overweight, administration of prostaglandins vaginally increases its bioavailability on uterus, which could improve their effectiveness for cervical maturation and induction of uterine contractions.

\subsection{Evolution of Labor and Maternal Prognosis}

The average dose received was $2.09 \pm 0.82$ or $104.5 \pm 41 \mu \mathrm{g}$ of Misoprostol. 66 (97.1\%) patients received 3 doses or less. Hafizur R et al. [1] also found an average of $2.33 \pm 1.18$ doses during labor induction with $50 \mu \mathrm{g}$ of oral Misoprostol. $97.1 \%$ had a normal course of labor and $2.9 \%$ had presented with uterine hyperstimulation. Hafizur et al. [1] found in their study $1.8 \%$ cases of uterine hypercinesia but did not find any case of hypertonia upon induction of labor. The fact that we monitored parturients only on the basis of clinical evidence for lack of cardiotocogram, we had difficulty differentiating hypercinesia from uterine hypertonia.

The mean time to onset of uterine contractions was $6.82 \pm 4.00$ hours and 38 (55.9\%) of patients already had uterine contractions after the first dose. 57 (83.8\%) of patients delivered within 24 hours. Saleh HS et al. [34] found a 96\% rate of vaginal delivery within 24 hours. The difference from our study would be related to the fact that they administered $50 \mu \mathrm{g}$ of Misoprostol every 4 hours with a maximum of 5 doses in a row if uterine contractions were not effective. Shetty A et al. [35] found a $93.3 \%$ of vaginal delivery within 24 hours within 24 hours. They administered $50 \mu \mathrm{g}$ of Misoprostol every 4 hours to patient with prelabor rupture of membranes.

The mean duration of labor was $16.03 \pm 7.99$ hours. Khadija $B$ et al. [36] found an average of $9.81 \pm 4.43$ hours probably because they administered $50 \mu \mathrm{g}$ every 4 hours. Snehil D et al. [37] found average labor duration of $10.84 \pm 3.37$ hours. This duration was less than that we found in our series because in their study, they only started labor in pregnant women with prelabor rupture of membranes, which can also induce labor and cause the cervical maturation. They administered $50 \mu \mathrm{g}$ of Misoprostol every 4 hours. Shetty et al. [35] found an average labor duration of 20.5 hours.

The failure rate was $2.9 \%$ (2 patients) in our series. Saleh HS et al. [34] had not found a case of failure and this would be linked to the frequency of administration and the total number of doses to be administered which was 5 doses, whereas in our series we set ourselves a total number of 3 to speak of failure. 2 
(2.9\%) patients delivered by caesarean section. Kahdija et al. [35] induced labor in pregnant women with a medical indication for induction and had found a rate of $41 \%$ of cesarean sections in a series of 100 pregnant women after induction with $50 \mu \mathrm{g}$ of oral Misoprostol every 4 hours. However, Saleh HS et al. [34] found a rate of $4 \%$ of caesarean section following the same protocol in pregnant women with term pregnancy without medical indication for induction of labor which can be in the same limits than our series.

\subsection{Perinatal Prognosis}

During labor, the rate of pathological modification of FHR was $2.9 \%$ (2 fetus). This rate is not different from that found by Saleh HS et al. [34] which was $2 \%$. 64 (94.1\%) newborns had an Apgar $\geq 7$ at the first minute versus 4 (5.9\%) who had a low Apgar. By the fifth minute, all newborns had an Apgar $\geq 7.66$ (97.1\%) newborns had a normal course. Saleh HS et al. [34] recorded no cases of Apgar < 7 at the first. It can be because of monitoring of labor by the cardiotocogram which can early detect pathological modification of FHR, then they could indicate early caesarian section.

\section{Conclusions}

Oral Misoprostol is effective in labor induction on term pregnancy, and is not associated with many maternal and perinatal complications. However, a BMI $\geq$ $25 \mathrm{~kg} / \mathrm{m}^{2}$ increases the risk of a prolonged duration of labor as well as the number of doses to be administered.

Research comparing the efficacy and safety of labor induction by oral Misoprostol versus sublingual, buccal or vaginal route following the same protocol, would be essential to improve the management of labor induction in under-equipped settings. It would also be essential to conduct studies on the labor induction in pregnant women with medical or obstetric indications and assess the maternal and perinatal prognosis.

The limitation of our study is that we conducted it in under-equipped settings without monitoring the FHR as uterine contractions. A larger sample could also be necessary to detect the other factor which could influence the number of dose, the duration of labor and the safety.

\section{Contributions from Authors}

Dr. Matega designed the project, the protocol, collected the data and wrote the manuscript. Dr. Matega, Wembakoy and Dr. Maindo had encoded and analyzed the data. Dr. Bosenge, Dr. Labama, Professors Juakali, Modia, Manga and Katenga had critically reviewed the content and validated the final version of the manuscript.

\section{Conflicts of Interest}

The authors declare no conflict of interest. 


\section{References}

[1] Hafizur, R., Anup, P., Latha, K., Prachi, R., Sumit, K. and Supid, D. (2013) Comparative Evaluation of 50 Microgram Oral Misoprostol and 25 Microgram Intravaginal Misoprostol for Induction of Labour at Term: A Randomized Trial. Journal of $O b$ stetrics and Gynaecology Canada, 35, 408-416. https://doi.org/10.1016/S1701-2163(15)30931-2

[2] Cunningham, F.G., Lenevo, K.J., Bloom, S.L., Spong, C.Y., Dashe, J.S., Hoffman, B., Casey, B. and Sheffield J. (2014) Williams Obstetrics. 24th Edition, McGraw-Hill Education, New York, 1358 p.

[3] Caughey, A.B. and Musci, T.J. (2004) Complications of Term Pregnancies beyond 37 Weeks of Gestation. Lippincott Williams and Wilkins, 103, 57-62. https://doi.org/10.1097/01.AOG.0000109216.24211.D4

[4] World Health Organization (2018) WHO Recommandations: Induction of Labour at or Beyond Term. World Health Organization, Geneva.

[5] Collège National des Gynécologues et Obstétriciens Français (2011) RCP Grossesse prolongée et terme dépassé. Collège National des Gynécologues et Obstétriciens Français (CNGOF), Paris. http://www.reseau-naissance.fr

[6] Abdulkadir, Y., Dejene, A., Geremew, M.A. and Dechasa, B. (2017) Induction of labor: Prevalence and Associated Factors for Its Outcome at Wolliso St. Luke, Catholic Hospital, South West Shewa, Oromia. Internal Medicine, 7, Article No. 255. https://doi.org/10.4172/2165-8048.1000255

[7] France Avril (2008) Déclenchement artificiel du travail à partir de 37 semaines d'aménorrhée. Recommendations pour la pratique Clinique de la Haute Autorité de Santé. http://www.has-sante.fr/portail/upload/docs/application/pdf

[8] Leduc, D., Biringer, A., Lee, L. and Dy, J. (2016) Déclenchement du Travail. Journal of Obstetrics and Gynaecology Canada, 38, S287-S310.

https://doi.org/10.1016/j.jogc.2016.09.040

[9] Justus Hofmeyr, G., Say, L. and Metin Gülmezoglu, A. (2005) WHO: Systematic Review of Maternal Mortality and Morbidity: The Prevalence of Uterine Rupture. BJOG: An International Journal of Obstetrics \& Gynaecology, 112, 1221-1228. https://doi.org/10.1111/j.1471-0528.2005.00725.x

[10] World Health Organization (2010) Global Survery on Maternal and Perinatal Health. World Health Organization, Geneva.

[11] Little, S.R. (2017) Elective Induction of Labor: What Is the Impact? Obstetrics and Gynecology Clinics of North America, 44, 601-614. https://doi.org/10.1016/j.ogc.2017.08.005

[12] Mbele, A.M., Makin, J.D. and Pattinson, R.C. (2007) Can the Outcome of Induction of Labor with Oral Misoprostol Be Predicted? South African Medical Journal, 97, 289-292.

[13] Oshodi, Y., Agbara, J., Fabamwo, A., Oyedele, Y., Akinlufu, F. and Ottun, T. (2017) Feto-Maternal Outcome of Induced versus Spontaneous Labour in Nigerian Tertiary Maternity Unit. Tropical Journal of Obstetrics and Gynaecology, 34, 21-27. https://doi.org/10.4103/TJOG.TJOG_59_16

[14] Tandu-Umba, B., Laala, T. and Mbangama, M. (2013) Maternal and Perinatal Outcomes of Induction of Labor at Term in the University Clinics of Kinshasa, DR Congo. Open Journal of Obstetrics and Gynecology, No. 3, 154-157.

[15] World Health Organization (2011) Recommandations for Induction of Labour. World Health Organization, Geneva. 
[16] Hossam, S., Ismall, M. and Ashraf, H. (2018) Comparative Study between Sublingual and Vaginal Misoprostol for Induction of Labor in Post Term Patients with Unfavourable Cervix. The Egyptian Journal of Hospital Medecine, 72, 4707-4711. https://doi.org/10.21608/ejhm.2018.9845

[17] Ambreen, A., Waseem, T., Nabecla, S. and Shaila, A. (2011) Induction of Labor. A Comparison between Misoprostol and Dinoprostol. Pakistan Journal of Medical \& Health Sciences, 5, Article No. 620.

[18] World Health Organization (2018) Recommendations: Induction of Labour at or Beyond Term. World Health Organization, Geneva.

[19] Vidal (2018) Misoprostol. http://www.vidal.fr

[20] Jindal, P., Avatshi, K. and Kaur, M. (2011) A Comparative of Vaginal versus Oral Misoprostol for Induction of Lavor. Double Blinding Randomized Trial. The Journal of Obstetrics and Gynecology of India, 61, 538-542. https://doi.org/10.1007/s13224-011-0081-0

[21] Weeks, A., Alfirevic, Z., Faundes, A., Hofmeyr, G.J., Safar, P. and Wing, D. (2007) Misoprostol for Induction of Labour with an Alive Fetus. International Journal of Gynecology and Obstetrics, 99, s164-s197. https://doi.org/10.1016/j.ijgo.2007.09.011

[22] FIGO (2017) Misoprostol-Only Recommended Regimes 2017. http://www.figo.org

[23] Pimentel, V.M., Arabkhazaeli, M., Moon, J.Y., Wang, A., Kapedani, A., Bernstein, P.S. and Tropper, P.J. (2018) Induction of Labor Using One Dose vs Multiple Doses of Misoprostol: A Randomized Controlled Trial. American Journal of Obstetrics \& Gynecology, 218, 614.e1-614.e8. https://doi.org/10.1016/j.ajog.2018.03.034

[24] Alexina, E., Sarah, J. and Lone, K. (2020) Induction of Labour in Nulliparous Women-Quick or Slow: A Short Study Comparing Slow-Release Vaginal Insert with Low-Dose Misoprostol Oral Tablets. Eriksson BCM Pregnancy and Childbirth, 20, Article No. 79. https://doi.org/10.1186/s12884-020-2770-0

[25] Azubuike, I.J., Bassey, G. and Okpani, A.O.U. (2015) Comparison of 25 and $50 \mathrm{Mi}-$ crogram of Misoprostol for Induction of Labor in Nulliparous Women with Postdate Pregnancy in Port Harcourt. Nigerian Journal of Clinical Practice, 18, 263-267. https://doi.org/10.4103/1119-3077.151056

[26] Alfirevic, Z. and Weeks, A. (2006) Oral Misoprostol for Induction of Labour. Cochrane Database of Systematic Reviews, No. 2, Article ID: CD001338. https://doi.org/10.1002/14651858.CD001338.pub2

[27] Vogel, J., West, H. and Dowswell, T. (2013) Titrated Oral Misoprostol for Augmenting Labour to Improve Maternal and Neonatal Outcomes. Cochrane Database of Systematic Reviews, No. 7, Article ID: CD010648. https://doi.org/10.1002/14651858.CD010648

[28] Traissac, P., Delpeuch, F., Maire, B., Martin, P.Y., Cornu, A. and Trèche, S. (1997) Construction d'un indice synthétique de niveau socio-économique des ménages dans les enquêtes nutritionnelles-Exemple d'application au Congo. Construction d' un indice synthétique de niveau socio-économique, 45, 114-115.

[29] Ferrazzi, E., Brembilla, G., Cipriani, S., Livio, S., Paganelli, A. and Parazzini, F. (2019) Maternal Age and Body Mass Index at Term: Risk Factors for Requiring and Induced Labour for a Late-Term Pregnancy. European Journal of Obstetrics \& Gynecology and Reproductive Biology, 223, 151-157.

https://doi.org/10.1016/j.ejogrb.2018.12.018

[30] Beckwith, L., Magner, K., Kritzer, S. and Warshak C.R. (2017) Prostaglandin versus Mechanical Dilatation and the Effect of Maternal Obesity on Failure to Achieve Active Labor: A Cohort Study. The Journal of Maternal-Fetal \& Neonatal Medicine, 
30, 1621-1626. https://doi.org/10.1080/14767058.2016.1220523

[31] Lassiter, J.R., Holliday, N., Lewis, D., Mulekar, M., Abshire, J. and Brocato, B. (2016) Induction of Labor with an Unfavorable Cervix: How Does BMI Affect Success? The Journal of Maternal-Fetal \& Neonatal Medecine, 29, 3000-3002. https://doi.org/10.3109/14767058.2015.1112371

[32] Maged, A.M., El-Semary, A.M., Marie H.M., Belal, D.S., Hany, A., Taymour, M.A., Omran, E.M., et al. (2018) Effect of Maternal Obesity on Labor Induction in Postdate Pregnancy. Archives of Gynecology and Obstetrics, 298, 45-50.

[33] Pevzner, L., Rayburn, W.F., Rumney, P. and Wing, D.A. (2009) Factor Predicting Successful Labor Induction with Dinoprostone and Misoprostol Vaginal Inserts. Obstetrics \& Gynecology, 114, 261-267.

https://doi.org/10.1097/AOG.0b013e3181ad9377

[34] Saleh, H.S. and Mowafy, H.E. (2016) Titrated Oral Misoprostol as a Safe Route for Induction of Labour at Term (A Clinical Trial). MOJ Women's Health, 3, 172-176. https://doi.org/10.15406/mojwh.2016.03.00058

[35] Shetty, A., Stewart, K., Stewart, G., Rice, P., Danielian, P. and Templeton, A. (2002) Active Management of Term Prelabour Rupture of Membranes with Oral Misoprostol. BJOG: An International Journal of Obstetrics \& Gynaecology, 109, 1354-1358. https://doi.org/10.1046/j.1471-0528.2002.02082.x

[36] Khadija, B., Mahjabeen, B. and Shereen, Z.B. (2009) Oral versus Vaginal Misoprostol for Induction of Labour at Term. Journal of Surgery Pakistan, 14, 38-41.

[37] Snehil, D., Singh, P. and Pritam, A. (2019) A Prospective Study to Assess Effectiveness of Oral Misoprostol in Active Management of Prelabour Rupture of Membrane at or After 36 Weeks of Pregnancy. International Journal of Medical and Health Research, 5, 210-2012. 


\section{Appendix: The Standard Protocol}

\section{Structure: \\ $\mathrm{N}^{\circ}$ Serie: \\ STANDARD PROTOCOL}

Title: Labor induction with oral Misoprostol in term pregnancy. A clinical trial

Date:

Age:

Marital status: Married $\square$; Single

Profession:

Education level: Illiterate $\square$; Primary $\square$; Secondary $\square$; Superior $\square$

Socio-economic level:

- Daily expenditure: $<17$ USD $\square ; \geq 17$ USD

- Habitat type: Non-durable materials $\square$; Durable materials

- Means of transport: Shared vehicle $\square$; Personal vehicle

Antecedents: Gestity Parity Abortion

$>$ Current pregnancy: Date of last period Gestational age

Prenatal consultations: Yes $\square$; Not $\square$

First trimester ultrasound: Yes $\square$; Not $\square$

If yes, probable term of pregnancy

Course of pregnancy: Normal $\square$; Risk $\square$; Type de risk

* Physical and obstetrical examination:

Temperature ${ }^{\circ} \mathrm{C}$; Arterial pressure $\mathrm{mmHg}$; Weight $\mathrm{Kg}$; Cut $\mathrm{m}$

Uterine height $\mathrm{cm}$; Fetal heart rate bpm

Condition of membranes: Intact Ruptured Since hours

* Indication of labor induction:

Term pregnancy $\square$; Postdate ( $\geq 41$ weeks) Postterm

Prelabor rupture of membranes $\square$; Intrauterine growth retardation

Preeclampsia $\square$; diabetes $\square$; Oligoamnios; $\square$ Other (Specify)

* Labor induction:

\begin{tabular}{|c|c|}
\hline$>$ Misoprostol $50 \mu \mathrm{g}\left(1 / 4\right.$ table $1^{\text {st }}$ day $)$ & $>$ Misoprostol $50 \mu \mathrm{g}\left(1 / 4\right.$ tablet $2^{\text {nd }}$ day $)$ \\
\hline $1^{\text {st }}$ dose: date ............ Time ............ & $1^{\text {st }}$ dose: date ............... Hours ........... \\
\hline $\begin{array}{l}\text { Time of onset of uterine contractions: .... } \\
\text { hours }\end{array}$ & $\begin{array}{l}\text { Time of onset of uterine contractions } / 1^{\text {st }} \\
\text { dose: .......... hours }\end{array}$ \\
\hline $2^{\text {nd }}$ dose: date .............. Hours . & $2^{\text {nd }}$ dose: date ........... Hours ... \\
\hline $\begin{array}{l}\text { Time of onset of uterine contractions } / 1^{\text {st }} \\
\text { dose: ..... hours }\end{array}$ & $\begin{array}{l}\text { Time of onset of uterine contractions } / 1^{\text {st }} \\
\text { dose: ...... hours }\end{array}$ \\
\hline $3^{\text {rd }}$ dose: date $. . . . \ldots \ldots .$. Hours .............. & 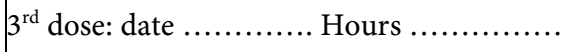 \\
\hline $\begin{array}{l}\text { Time of onset of uterine contractions } / 1^{\text {st }} \\
\text { dose ..... hours }\end{array}$ & $\begin{array}{l}\text { Time of onset of uterine contractions } / 1^{\text {st }} \\
\text { dose ..... hours }\end{array}$ \\
\hline
\end{tabular}

Use of oxytocin solution: Yes $\square$; Not $\square$; Time limit/ $1^{\text {st }}$ dose: 
Bishop score:

Rupture of membranes: Time hours

Appearance of amniotic fluid: clear $\square$; meconium

Unfolding of labor: Normale $\square$; hyperstimulation $\square$; Pathological modification of FHR

Side effects: Diarrhea $\square$; Vomiting $\square$; Fever $\square$; Chills $\square$; Other

Duration of latent phase $(0-3 \mathrm{~cm})$ Hours

* Delivery

Time: ; Time limit/1 ${ }^{\text {ère }}$ dose: hours

$>$ Vaginal delivery

Cesarean section

Indication of cesarean section: Pathological modification of FHR $\square$; hyperstimulation $\square$; Failed labor induction $\square$; Other (specify)

New born: Sex: Male $\square$; Feminine $\square$

Weight: gr; Apgar: $1^{\text {st }}$ minute; $5^{\text {th }}$ minutes; A $10^{\text {th }}$ minutes

Neonatal management: Yes $\square$; NOT $\square$

If yes, Neonatal asphyxia $\square$; Neonatal infection $\square$; Other (specify):

Unfolding new born: Good $\square$; Neonatal care $\square$; Stillbirth

Maternal Complications

Pre-rupture $\square$; Uterine rupture $\square$; Other (specify):

Patient Satisfaction:

Not satisfied $\square$; Satisfied $\square$; Very satisfied

Provider's observations:

Thank you! 